\title{
Synthesis, Characterization and Biological Screening of Ferulic Acid Derivatives
}

\author{
T. Naga Ravi Kiran ${ }^{*}$, Ch. Sri Alekhya1, B. V. S. Lokesh1, A. V. S. Madhu Latha', \\ Y. Rajendra Prasad1, T. Naga Mounika1 \\ ${ }^{1}$ Department of Pharmaceutical Chemistry, Andhra University, Visakhapatnam, India \\ ${ }^{2}$ Nalanda Institute of Pharmaceutical Sciences, Sattenapalli, Guntur, India \\ Email: ${ }^{*}$ ravikirannaga58@gmail.com
}

Received 20 August 2015; accepted 21 September 2015; published 24 September 2015

Copyright (C) 2015 by authors and Scientific Research Publishing Inc.

This work is licensed under the Creative Commons Attribution International License (CC BY).

http://creativecommons.org/licenses/by/4.0/

(c) (i) Open Access

\begin{abstract}
According to WHO, cancer is a leading cause of death worldwide, accounting for 8.2 million deaths in 2012. Among several factors involved in the pathogenesis of cancer, free radical formation followed by damage to DNA and cell protein is one of the causes. Natural plant products have gained enormous interest in the prevention or treatment of chronic diseases. Ferulic acid, like other phenolic acids (caffeic acid, sinapic acid) possess anti cancer activity. A series of ferulic esters (FE1 - FE11) and ferulic amides (FA1 - FA10) were synthesized and evaluated for their cytotoxic activity.
\end{abstract}

\section{Keywords}

Ferulic Acid, Cytotoxicity, Hela (Cervical Cancer Cell Lines), A549 (Lung Cancer Cell Lines), HT-29 (Colorectal Cancer Cell Lines), Synthesis

\section{Introduction}

Natural plant products have gained enormous interest in the prevention or treatment of chronic diseases [1]. From the evolution to till date, whether on an empirical or rational basis, natural based molecules have long been used as drugs or drug leads. Several small molecules available worldwide on the drug market can be traced back to or were inspired by natural products. In the ongoing search for new therapeutic compounds, phenolic acids, which are widely distributed in plants [2], are usually available in cell wall as glycosidic conjugates or esters or amides, therefore they can be released from nature by alkaline hydrolysis [3]. Phenolic acids are widely

${ }^{*}$ Corresponding author.

How to cite this paper: Kiran, T.N.R., Alekhya, Ch.S., Lokesh, B.V.S., Latha, A.V.S.M., Prasad, Y.R. and Mounika, T.N. (2015) Synthesis, Characterization and Biological Screening of Ferulic Acid Derivatives. Journal of Cancer Therapy, 6, 917-931. http://dx.doi.org/10.4236/jct.2015.610100 
used as anti oxidants in various food products and cosmetics. Other applications of phenolic acids includes anti tumor, hypoglycemic, antihypertensive, anti inflammatory, anti oxidant etc. [4].

According to WHO, cancer is a leading cause of death worldwide, accounting for 8.2 million deaths in 2012. The number of new cases is expected to rise by about $70 \%$ over the next 2 decades. More than half of cancers occurring worldwide are in less developed regions. Among several factors involved in the pathogenesis of cancer, free radical formation followed by damage to DNA and cell protein is one of the causes. Ferulic acid, like other phenolic acids (caffeic acid, sinapic acid) possess anti cancer activity. FA scavenges the free radical, regulates cell growth and proliferation and stimulates cytoprotective enzymes and inhibits cytotoxic systems in both in vitro and in vivo experimental models [3].

Ferulic acid (4-hydroxy-3-methoxy cinnamic acid) is a phenolic acid found in seeds and leaves of most plants. It is biosynthesized from aminoacid phenylalanine through shikmic acid pathway. FA was first isolated from a commercial resin in 1866. Hlasiwetz Barth, an Austrian, isolated 3-methoxy-4-hydroxycinnamic acid from the genus Ferula foetida for structure determination [4]. FA serves to cross link the polysaccharides and proteins during lignin cell wall synthesis [5]. The synthesis of Ferulic acid was established by Dutt in 1935 [4], more over its chemical structure resembles that of curcumin. Ferulic acid [6], was used as a precursor in the manufacturing of vanillin and malonic acid. Numerous studies have shown that ferulic acid is a potent antioxidant, antitumor, hypoglycemic, UV-absorber, anti atherogenic, neuroprotective, anti inflammatory, anti-hyperlipidemic, anti platelet [7] etc. (Figure 1, Figure 2).

Ferulic acid exhibits antioxidant property through Free radical scavenging property via donating one hydrogen atom from its phenolic hydroxyl group [8] [9]. Ferulic acid and Ferulic acid ethyl ester (FAEE) have shown to regulate the key enzymes which were being responsible for free radical induced cell damage, such as heme oxygenase/biliverdin reductase (HO/BVR) system, superoxide dismutase (SOD), catalase (CAT) as well as the chaperone heat shock protein (Hsp)-70 [3] [10]. Fu-Hsiung Linl et al., have proved that addition of $0.5 \%$ of ferulic acid to $15 \%$ L-ascorbic acid and $1 \% \alpha$-tocopherol stabilizes the solution and doubled photo protection effect [5] [11].

FA has a structural resemblance to curcumin. A number of preclinical studies showed that curcumin, a component of the Indian spice (tumeric), has antioxidant and anti cancer properties [1].

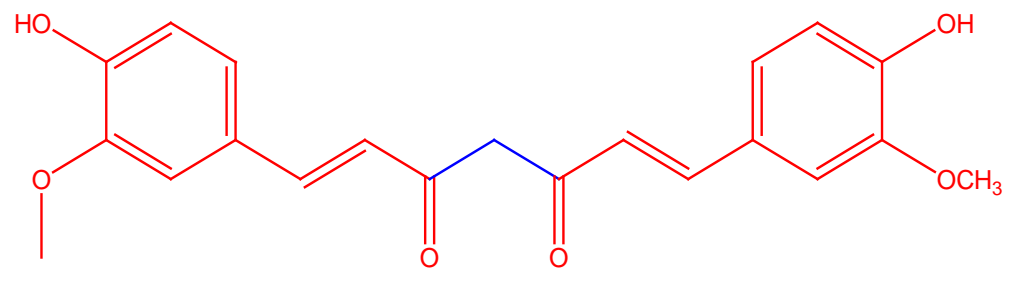

Curcumin

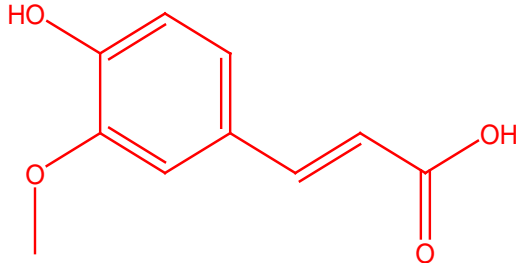

Ferulic acid

Anurag Khatkar et al., have synthesized various series of esters and amides of ferulic acid, and tested them for antimicrobial activity [12].

Owing to its diversified therapeutic application, our research work focused on synthesis and anti cancer evaluation of various ferulic esters and amides.

\section{Materials and Reagents}

Ferulic acid, Thionyl chloride, conc. $\mathrm{H}_{2} \mathrm{SO}_{4}$. R'-OH (R' as given in Table 1), $\mathrm{R}^{-} \mathrm{NH}_{2}$ (R as given in Table 3).

Potable water, Ethyl acetate, n-hexane, TLC plates (Merck pre-coated silica gel F plates), P-Anisaldehyde, ninhydrin (TLC visualizing agent).

Derivatives of ferulic acid (corresponding esters and amides) were synthesized using the following method.

\subsection{Scheme of Synthesis of Ferulic Esters}

Ferulic esters (FE1-FE11) were synthesized as outlined in Scheme 1. Ferulic acid (0.0102 moles) is added with appropriate alcohol (5 volumes), it was heated under reflux in presence of sulfuric acid for 4 hrs. The reaction 


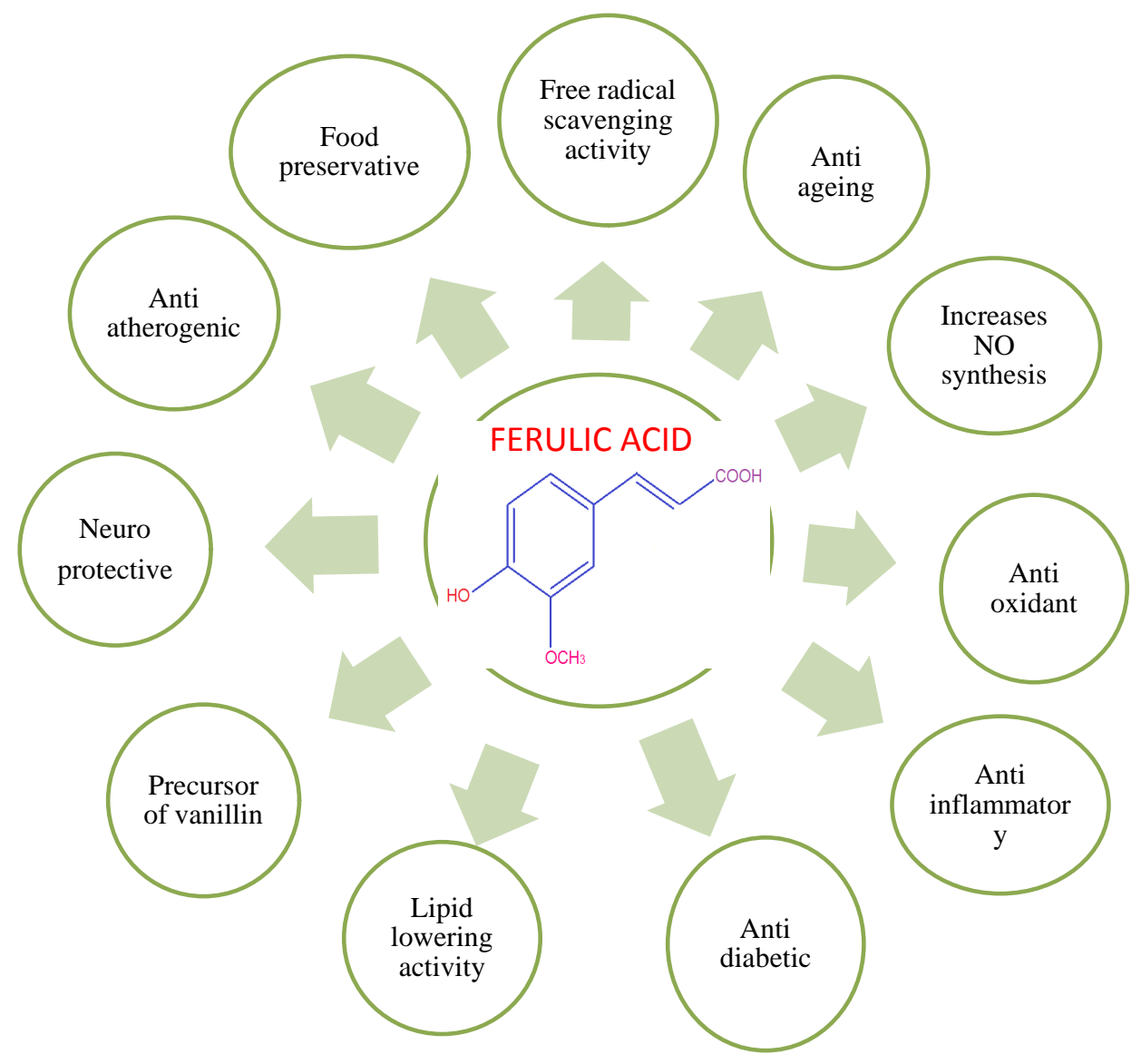

Figure 1. Potential applications of ferulic acid.
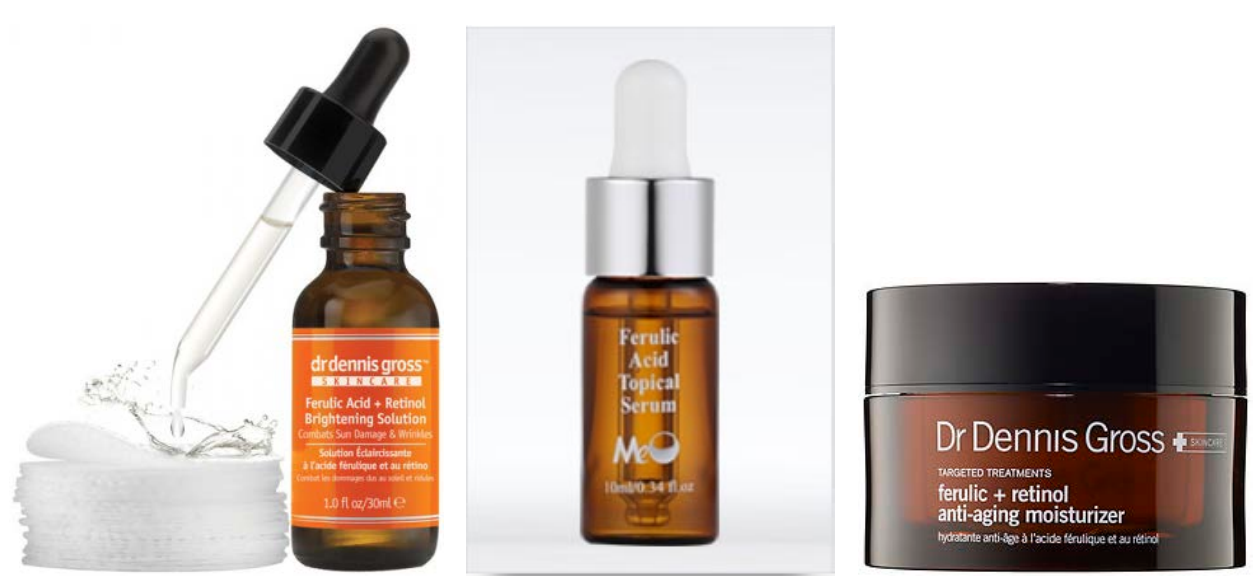

Figure 2. Various marketed formulations of ferulic acid.

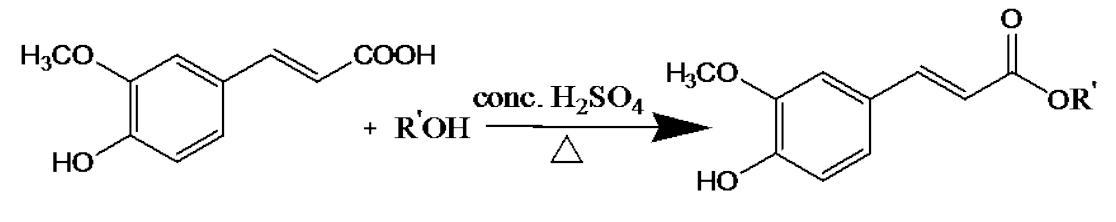

FE1-FE11

Scheme 1. Synthesis of ferulic esters. 
was monitored by TLC (Merck grade), the reaction mixture was purified through column chromatography (silica gel mesh 100/200) with 20\% ethyl acetate in hexane. The physicochemical properties were presented in Table 1. The structures of the all the synthesized compounds were confirmed by IR, ${ }^{1} \mathrm{H}$ NMR, ${ }^{13} \mathrm{C}$ NMR and Mass spectroscopy.

Compound FE1:

IR absorption bands ( $\left.\mathrm{cm}^{-1}\right) 3630$ (Ar-OH), 1635(C=O str., ester), 3010 (C-H str., aromatic), 1596 (C=C skeletal str., phenyl), 1699 (C=C str., alkene), $2860\left(\mathrm{C}-\mathrm{H}\right.$ str., $\left.\mathrm{Ar}-\mathrm{OCH}_{3}\right) ;{ }^{1} \mathrm{H}$ NMR spectrum $\left(400 \mathrm{MHz}, \mathrm{CDCl}_{3}\right.$, showed the characteristic signals of: 5.00 of $\mathrm{Ar}-\mathrm{OH}(\mathrm{s}, 1 \mathrm{H}), 3.91$ of- $-\mathrm{OCH}_{3}(\mathrm{~s}, 1 \mathrm{H}), 3.78$ of $\mathrm{Ar}-\mathrm{OCH}_{3}(\mathrm{~s}, 3 \mathrm{H})$, $7.630\left(\mathrm{~d}, 1 \mathrm{H}, \mathrm{C}_{1}\right.$ of acrylate, $\left.\mathrm{j}=1.2 \mathrm{~Hz}\right), 6.90\left(\mathrm{~d}, 1 \mathrm{H}, \mathrm{C}_{2}\right.$ of acrylate, $\left.\mathrm{j}=8 \mathrm{~Hz}\right),{ }^{13} \mathrm{C}$ NMR $(\delta \mathrm{ppm})$ spectrum of compound FE1 exhibited the characteristic signals at: $52.50\left(-\mathrm{OCH}_{3}\right), 56.2\left(\mathrm{Ar}-\mathrm{OCH}_{3}\right), 118.1\left(\mathrm{C}_{2} \mathrm{of}\right.$ acrylate), 143.7 ( $\mathrm{C}_{1}$ of acrylate).

Compound FE2:

IR absorption bands ( $\mathrm{cm}^{-1}$ ) 3600 (Ar-OH), 1685 (C=Ostr., ester), 3004 (C-H str., aromatic), 1592 (C=C skeletal str., phenyl), 1689 (C=C str., alkene), 1080 (C-O str. Ester), 2842 (C-H str., Ar-OCH3); ${ }^{1} \mathrm{H}$ NMRspectrum $\left(400 \mathrm{MHz}, \mathrm{CDCl}_{3}\right) 5.00 \mathrm{Ar}-\mathrm{OH}(\mathrm{s}, 1 \mathrm{H}), 3.91-\mathrm{OCH}_{3}(\mathrm{~s}, 1 \mathrm{H}), 3.78-\mathrm{ArOCH}_{3}(\mathrm{~s}, 3 \mathrm{H}), 7.630$ (d, $1 \mathrm{H}, \mathrm{C}_{1}$ of acrylate, $\mathrm{j}=1.2 \mathrm{~Hz}), 6.90\left(\mathrm{~d}, 1 \mathrm{H}, \mathrm{C}_{2}\right.$ of acrylate, j = 8 Hz) $6.37 \mathrm{Ar}-\mathrm{H}(\mathrm{d}, 1 \mathrm{H}, \mathrm{j}=1.6 \mathrm{~Hz}) 6.925 \mathrm{Ar}-\mathrm{H}(\mathrm{d}, 1 \mathrm{H}, \mathrm{j}=1.6 \mathrm{~Hz})$.

Compound FE3:

IR absorption bands cm ${ }^{-1} 3620$ (Ar-OH), 1675 (C=Ostr., ester), 3006 (C-H str., aromatic), 1589 (C=C skeletal str., phenyl), 1685 (C=C str., alkene), 1095 (C-O str. Ester), 2946 (C-H str., Ar-OCH3) 710.94 (long chain band); 5.890 (1H s Ar-OH), $3.924\left(1 \mathrm{H}, \mathrm{s}, \mathrm{OCH}_{3}\right),{ }^{1} \mathrm{H}$ NMRspectrum 3.88- $\mathrm{ArOCH}_{3}(\mathrm{~s}, 3 \mathrm{H}), 7.059$ (d, 1H, $\mathrm{C}_{1}$ of acrylate, j = 3.6 Hz), 6.275 (s, 1H, $\mathrm{C}_{2}$ of acrylate) $6.904 \mathrm{Ar}-\mathrm{H}(\mathrm{d}, 1 \mathrm{H} \mathrm{j}=1.2 \mathrm{~Hz}) 7.036 \mathrm{Ar}-\mathrm{H}(\mathrm{d}, 1 \mathrm{H} \mathrm{j}=4.4 \mathrm{~Hz})$ $1.012 \mathrm{CH}_{3}$ of propyl chain, (m3H) $1.682 \mathrm{CH}_{2}$ of propyl chain, (m, $\left.2 \mathrm{H}\right) 4.174 \mathrm{CH}_{2}$ of n-propyl chain, $(\mathrm{m}, 2 \mathrm{H})$.

\subsubsection{Cytotoxicity Studies by MTT Assay Method}

\section{Maintainence of cell lines:}

HT-29 and A-549 cells were grown as adherent in DMEM media, whereas Hela cells were grown in MEM media supplemented with $10 \%$ fetal bovine serum the culture was maintained in a humidified atmosphere with $5 \% \mathrm{CO}_{2}$.

\section{MTT assay method:}

The cells (HT29, Hela, A549) were seeded in 96 well plate at a density of $1 * 10^{4}$ (counted by tryphan blue exclusion dye method) per wall and were incubated for 24 hrs to recover. After incubation, the medium was replaced with fresh media containing different dilutions of test compounds. Then the plates were incubated for additional $48 \mathrm{hr}$ at $37^{\circ}$ in DMEM (Dulbeccos Eagles medium), /MEM (Minimum essential media eagle) with 10\% FBS (fetal bovine serum) medium. Following incubation, the medium was removed and replated with $90 \mu \mathrm{l}$ of fresh DMEM without FBS. To the above wells, $10 \mu \mathrm{l}$ of MTT [3-(4,5-dimethyl thiazol-2-yl)-2,5-diphenyl tetrazoliun bromide] reagent was added and incubated at $37^{\circ}$ for $10 \mathrm{~min}$. The absorbance at $570 \mathrm{~nm}$ was measured on a UV spectrophotometer [13] [14].

Methotrexate was used as reference drug for comparison. Assay was performed in triplicate for three independent determinations. The cytotoxicity was expressed as $\mathrm{IC}_{50}(\mu \mathrm{g} / \mathrm{ml})$ which is the concentration of the compound that inhibited proliferation rate of the tumor cells by $50 \%$ as compared to the control untreated cells. $\mathrm{IC}_{50}$ values were determined from the plot i.e., \% inhibition versus concentration (Table 2) (Supplementary Data).

$$
\% \text { Inhibition of the given concentration }=\frac{1-(\text { Absorbance average })}{\text { control absorbance average }} * 100
$$

\subsubsection{Results and Discussion}

In a nutshell, it is evident that all the synthesized esters of Ferulic acid are having good cytotoxic activity with different IC $_{50}$ values against three cell lines (Hela, HT-29, A-549). Methotrexate was used as standard. Of all the compounds tested against HT-29 cell lines, FE10 having a chloroethyl group showed maximum cytotoxicity with a $\mathrm{IC}_{50}$ value of $19 \mu \mathrm{g} / \mathrm{mL}$. Down the order, FE11-having bromine group $\left(\mathrm{IC}_{50}=50 \mu \mathrm{g} / \mathrm{mL}\right.$ ) FE5-having nbutyl chain $\left(\mathrm{IC}_{50}=74 \mu \mathrm{g} / \mathrm{mL}\right)$. FE3 having n-propyl chain $\left(\mathrm{IC}_{50}=75 \mu \mathrm{g} / \mathrm{mL}\right.$ ) follows. The other compounds were also moderately potent but with higher $\mathrm{IC}_{50}$ values. The potency indicated the importance of halogen in enhancing the cytotoxicity; and as the chain length increases cytoxicity increases. Neverthless, branching of the 
Table 1. Physical characterization of esters (FE1 - FE11).

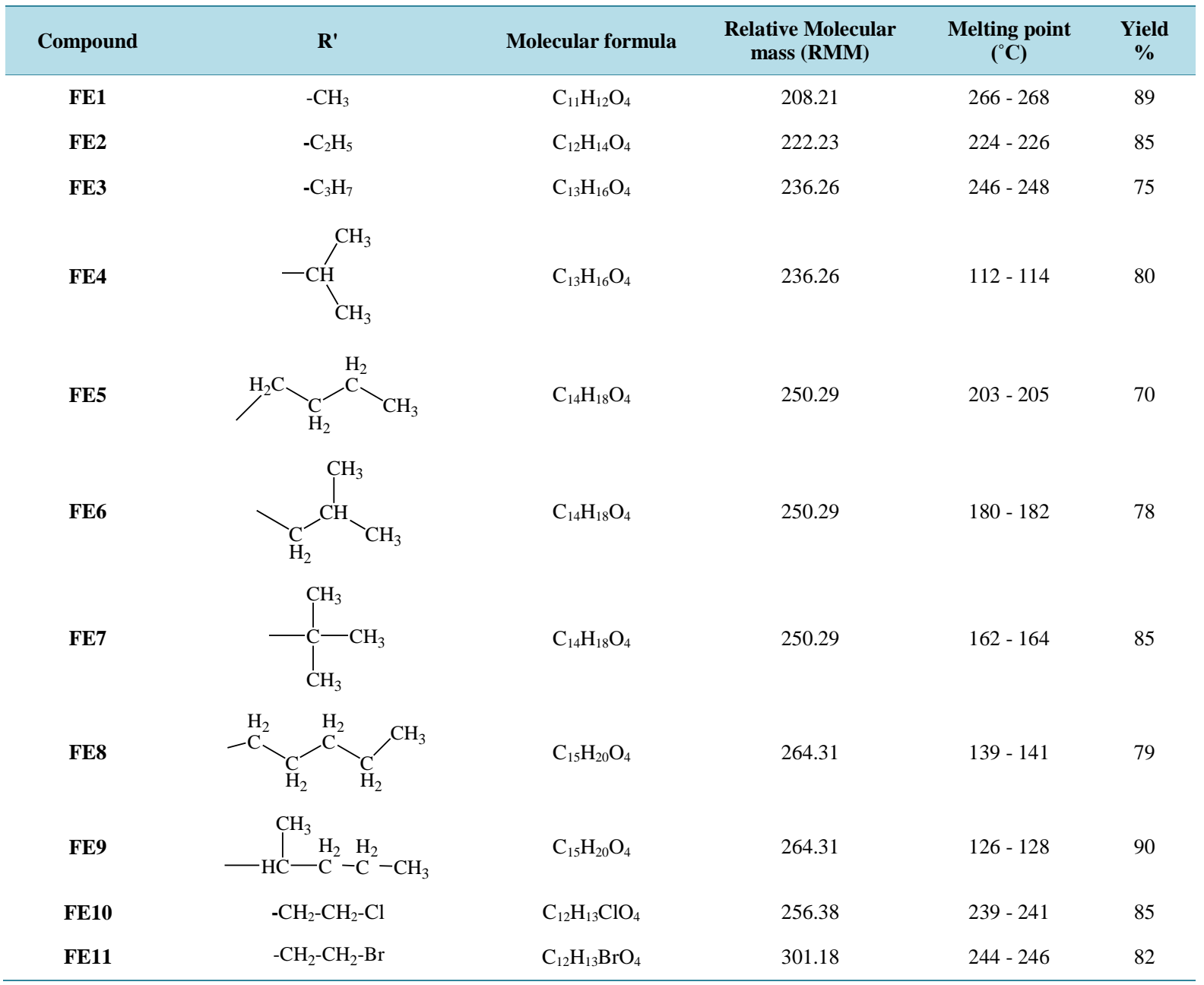

Table 2. Cytotoxicity of ferulic esters.

\begin{tabular}{|c|c|c|c|c|}
\hline \multirow{2}{*}{ Compound } & \multirow{2}{*}{$\mathbf{R}^{\prime}$} & \multicolumn{3}{|c|}{ Cell lines } \\
\hline & & HT-29 & HELA & A-549 \\
\hline FE1 & Methyl & $126 \pm 1$ & $92 \pm 2$ & $101 \pm 2$ \\
\hline FE2 & Ethyl & $94 \pm 2$ & $70 \pm 2$ & $92 \pm 1$ \\
\hline FE3 & n-propyl & $75 \pm 2$ & $64 \pm 2$ & $60 \pm 1$ \\
\hline FE4 & Isopropyl & $92 \pm 2$ & $138 \pm 2$ & NA \\
\hline FE5 & n-butyl & $74 \pm 1$ & $61 \pm 2$ & $83 \pm 2$ \\
\hline FE6 & Isobutyl & $96 \pm 1$ & $105 \pm 2$ & NA \\
\hline FE7 & t-butyl & NA & $127 \pm 2$ & $108 \pm 1$ \\
\hline FE8 & n-pentyl & $77 \pm 1$ & $69 \pm 1$ & $95 \pm 1$ \\
\hline FE9 & 2-pentyl & $92 \pm 2$ & $89 \pm 2$ & $98 \pm 2$ \\
\hline FE10 & Chloro ethyl & $19 \pm 2$ & $32 \pm 1$ & $43 \pm 2$ \\
\hline FE11 & Bromo ethyl & $50 \pm 2$ & $55 \pm 2$ & $20 \pm 1$ \\
\hline Methotrexate & & $12 \pm 1$ & $9 \pm 1$ & $5 \pm 1$ \\
\hline
\end{tabular}


chain diminish the activity.

Among the compounds tested against HeLa cell lines, FE10 having a chlorine group exhibited maximum cytotoxicity with a $\mathrm{IC}_{50}$ value of $32 \mathrm{\mu g} / \mathrm{mL}$. This is followed by compounds, FE11-having bromine group $\left(\mathrm{IC}_{50}=\right.$ $55 \mu \mathrm{g} / \mathrm{mL}$ ), FE5-having n-butyl chain ( $\mathrm{IC}_{50}=61 \mu \mathrm{g} / \mathrm{mL}$ ), FE3-having npropyl chain $\left(\mathrm{IC}_{50}=64 \mu \mathrm{g} / \mathrm{mL}\right)$. The other compounds were also moderately potent, but with higher $\mathrm{IC}_{50}$ values. The potency may be due to the presence of halogen, which enhances the cytotoxicity. As the chain length increases, cytoxicity increases. However branching of the chain hinders the activity.

Among the compounds tested against A-549 cell lines, FE11 having a bromine group showed maximal cytotoxicity with a $\mathrm{IC}_{50}$ value of $20 \mu \mathrm{g} / \mathrm{mL}$. This is followed by compounds, FE10, having chlorine group $\left(\mathrm{IC}_{50}=43\right.$ $\mu \mathrm{g} / \mathrm{mL}$ ), FE5-having n-propyl chain ( $\mathrm{IC}_{50}=60 \mu \mathrm{g} / \mathrm{mL}$ ), FE3, having n-butyl chain $\left(\mathrm{IC}_{50}=83 \mu \mathrm{g} / \mathrm{mL}\right.$ ). The other compounds also showed the activity but at a higher $\mathrm{IC}_{50}$ values. The results indicated the importance of presence of a halogen in enhancing the cytotoxicity. As the chain length increases cytoxicity increases. But branching of the chain reduces the activity.

\subsection{Scheme of Synthesis of Ferulic Amides}

Ferulic amides (FA1-FA11) were synthesized as outlined in Scheme 2. Ferulic acid (0.0102 moles) is added with Thionyl chloride $\left(0.0102\right.$ moles) and heated to $60^{\circ} \mathrm{C}$ for $1 \mathrm{hr}$. A pale yellow residue was observed. The acid chloride was then treated with amines in THF $\left(\mathrm{R}-\mathrm{NH}_{2}, 10 \mathrm{ml}\right)$ and stirred at $0^{\circ} \mathrm{C}-10^{\circ} \mathrm{C}$ using a guard tube (made of $\mathrm{Cacl}_{2}$ ). The reaction is monitored using TLC, the reaction mixture was purified through column chromatography (silica gel mesh 100/200) with 30\% ethyl acetate in hexane as mobile phase. The physicochemical properties were presented in Table 3 . The structures of the all the synthesized compounds were confirmed by IR, ${ }^{1} \mathrm{H}$ NMR, ${ }^{13} \mathrm{C}$ NMR and Mass spectroscopy.

Compound FA1:

The IR $\left(\mathrm{cm}^{-1}\right)$ spectrum, showed the characteristic absorption bands at 3598.78 (Ar-OH), 3089.74 (C-H str. Alkenes), 3398.78 (NH str.). 1699.44 (C=O str. Amides); The ${ }^{1} \mathrm{H}$ NMR spectrum (400 MHz, $\mathrm{CDCl}_{3}$,) showed the characteristic signals of $5.20 \mathrm{Ar}-\mathrm{OH}(\mathrm{s}, 1 \mathrm{H}), 3.91-\mathrm{OCH}_{3}(\mathrm{~s}, 1 \mathrm{H}), 3.88 \mathrm{Ar}^{-\mathrm{OCH}_{3}}(\mathrm{~s}, 3 \mathrm{H}), 7.09\left(\mathrm{~d}, 1 \mathrm{H}, \mathrm{C}_{1}\right.$ of acrylate, $\mathrm{j}=16 \mathrm{~Hz}), 6.290\left(\mathrm{~s}, 1 \mathrm{H}, \mathrm{C}_{2}\right.$ of acrylate) $6.67 \mathrm{Ar}-\mathrm{H}(\mathrm{d}, 1 \mathrm{H} \mathrm{j}=15.2 \mathrm{~Hz}), 6.825 \mathrm{Ar}-\mathrm{H}(\mathrm{d}, 1 \mathrm{H} \mathrm{j}=8.4 \mathrm{~Hz})$, $6.005\left(\mathrm{~s}, 2 \mathrm{H}, \mathrm{NH}_{2}\right)$.

Compound FA2:

IR absorption bands ( $\left.\mathrm{cm}^{-1}\right) 3630$ (Ar-OH), $3119\left(\mathrm{NH}_{2}\right), 1653$ (C=O str., amide) 3018 (C-H str., aromatic), 1565 (C=C skeletal str., phenyl), 1689 (C=C str., alkene), 2865 (C-H str., $\mathrm{Ar}-\mathrm{OCH} 3) 2855\left(\mathrm{CH}_{3}\right.$ str.,). The ${ }^{1} \mathrm{H}$ NMR spectrum (400 MHz, CDCl ${ }_{3}$ ) $.88 \mathrm{Ar}-\mathrm{OH}(\mathrm{s}, 1 \mathrm{H}), 3.79-\mathrm{OCH}_{3}(\mathrm{~s}, 1 \mathrm{H}), 3.45 \mathrm{Ar}-\mathrm{OCH}_{3}(\mathrm{~s}, 3 \mathrm{H}), 7.29$ (d, $1 \mathrm{H}$, $\mathrm{C}_{1}$ of acrylate, $\left.\mathrm{j}=12 \mathrm{~Hz}\right), 6.390\left(\mathrm{~d}, 1 \mathrm{H}, \mathrm{C}_{2}\right.$ of acrylate, $\left.\mathrm{j}=2 \mathrm{~Hz}\right), 6.77 \mathrm{Ar}-\mathrm{H}(\mathrm{d}, 1 \mathrm{H} \mathrm{j}=8 \mathrm{~Hz}), 6.925 \mathrm{Ar}-\mathrm{H}(\mathrm{d}, 1 \mathrm{H}$ $\mathrm{j}=26 \mathrm{~Hz}), 8.005\left(\mathrm{~s}, 2 \mathrm{H}, \mathrm{NH}_{2}\right), 2.75\left(\mathrm{~s}, 3 \mathrm{H}, \mathrm{CH}_{3}\right)$.

\subsubsection{Cytotoxicity Studies by MTT Assay Method}

The Method followed was same as that of ferulic esters $(\mathrm{FE1-11)}$ (Table 4).

\subsubsection{Results and Discussion}

In a nutshell, it is evident that all the synthesized amides of Ferulic acid are having good cytotoxic activity with different $\mathrm{IC}_{50}$ values against three cell lines (Hela, HT-29, A-549), Methotrexate was used as standard drug. Of all the compounds tested against HT-29 cell lines, FA10 having a morpholine showed maximum cytotoxicity with a $\mathrm{IC}_{50}$ value of $18 \mu \mathrm{g} / \mathrm{mL}$. This is followed by compounds, FA6 with p-amino benztrifluroide $\left(\mathrm{IC}_{50}=19\right.$ $\mu \mathrm{g} / \mathrm{mL}$ ) FA1-a simple amide $\left(\mathrm{IC}_{50}=20 \mu \mathrm{g} / \mathrm{mL}\right.$ ), FA9-having p-fluoro benzyl $\left(\mathrm{IC}_{50}=30 \mu \mathrm{g} / \mathrm{mL}\right.$ ), FA4-with benzyl moiety $\left(\mathrm{IC}_{50}=38 \mu \mathrm{g} / \mathrm{mL}\right.$ ). The other compounds were also moderately potent but with higher $\mathrm{IC}_{50}$ values. The potency indicated the importance of halogen in enhancing the cytotoxicity.

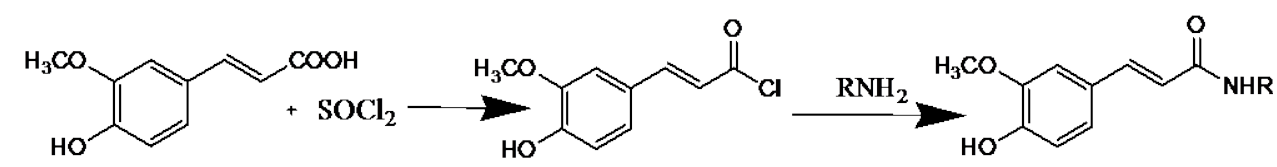

FA1-FA10 
Table 3. Physical characterization of amides (FA1 - FA10).

\begin{tabular}{|c|c|c|c|c|c|}
\hline Compound & $\mathbf{R}$ & Molecular formula & $\begin{array}{l}\text { Relative Molecular mass } \\
\text { (RMM) }\end{array}$ & $\begin{array}{l}\text { Melting point } \\
\left({ }^{\circ} \mathrm{C}\right)\end{array}$ & $\begin{array}{c}\text { Yield } \\
\%\end{array}$ \\
\hline FA1 & $-\mathrm{H}$ & $\mathrm{C}_{10} \mathrm{H}_{11} \mathrm{NO}_{3}$ & 193.19 & $206-208$ & 80 \\
\hline FA2 & $-\mathrm{CH}_{3}$ & $\mathrm{C}_{11} \mathrm{H}_{13} \mathrm{NO}_{3}$ & 207.23 & $224-226$ & 82 \\
\hline FA3 & $-\mathrm{C}_{2} \mathrm{H}_{5}$ & $\mathrm{C}_{12} \mathrm{H}_{15} \mathrm{NO}_{3}$ & 221.25 & $230-232$ & 75 \\
\hline FA4 & & $\mathrm{C}_{17} \mathrm{H}_{17} \mathrm{NO}_{3}$ & 283.32 & $146-148$ & 79 \\
\hline FA5 & & $\mathrm{C}_{16} \mathrm{H}_{15} \mathrm{NO}_{3}$ & 269.29 & $150-152$ & 75 \\
\hline FA6 & & $\mathrm{C}_{17} \mathrm{H}_{14} \mathrm{~F}_{3} \mathrm{NO}_{3}$ & 337.29 & $145-147$ & 87 \\
\hline FA7 & & $\mathrm{C}_{17} \mathrm{H}_{14} \mathrm{~N}_{2} \mathrm{O}_{3}$ & 294.304 & $200-202$ & 70 \\
\hline FA8 & & $\mathrm{C}_{16} \mathrm{H}_{15} \mathrm{NO}_{4}$ & 285.29 & $230-232$ & 75 \\
\hline FA9 & & $\mathrm{C}_{17} \mathrm{H}_{16} \mathrm{FNO}_{3}$ & 319.75 & $228-230$ & 80 \\
\hline FA10 & & $\mathrm{C}_{14} \mathrm{H}_{17} \mathrm{NO}_{4}$ & 263.28 & $250-252$ & 75 \\
\hline
\end{tabular}


Table 4. Cytotoxicity of ferulic amides.

\begin{tabular}{ccccc}
\hline Compound & R & Cell line & \\
\cline { 2 - 4 } & & HT-29 & HELA & A-549 \\
FA1 & H & $20 \pm 2$ & $35 \pm 2$ & $18 \pm 1$ \\
FA2 & Methyl & $55 \pm 2$ & $45 \pm 1$ & $40 \pm 1$ \\
FA3 & Ethyl & $50 \pm 1$ & NA & $70 \pm 2$ \\
FA4 & Benzyl & $38 \pm 1$ & $65 \pm 2$ & $50 \pm 2$ \\
FA5 & Aniline & $90 \pm 1$ & $120 \pm 2$ & $66 \pm 1$ \\
FA6 & 4-amino benztrifluoride & $19 \pm 2$ & $38 \pm 2$ & $72 \pm 1$ \\
FA7 & Amino benz nitrile & NA & $80 \pm 2$ & $40 \pm 2$ \\
FA8 & p-hydroxy aniline & $50 \pm 2$ & $25 \pm 2$ & $55 \pm 2$ \\
FA9 & p-fluoro benzyl & $30 \pm 1$ & $23 \pm 1$ & $30 \pm 1$ \\
FA10 & Morpholine & $18 \pm 2$ & $9 \pm 1$ & $5 \pm 1$ \\
Methotrexate & & $12 \pm 1$ & & \\
\hline
\end{tabular}

Among the compounds tested against Hela cell lines, FA10 having a morpholine group showed maximum cytotoxicity with a $\mathrm{IC}_{50}$ value of $23 \mu \mathrm{g} / \mathrm{mL}$. This is followed by compounds, FA9 with p-fluoro benzyl $\left(\mathrm{IC}_{50}=\right.$ $25 \mu \mathrm{g} / \mathrm{mL}$ ), FA1, a simple amide ( $\mathrm{IC}_{50}=35 \mu \mathrm{g} / \mathrm{mL}$ ). FA6 having p-amino benztrifluroide $\left(\mathrm{IC}_{50}=38 \mu \mathrm{g} / \mathrm{mL}\right.$ ). The other compounds were also moderately potent but with a higher $\mathrm{IC}_{50}$ values. The potency indicated the importance of halogen in enhancing the cytotoxicity.

Among the compounds tested against A-549 cell lines, FA1 simple amide showed maximum cytotoxicity with a IC I0 $_{0}$ value of $18 \mu \mathrm{g} / \mathrm{mL}$. This is followed by compounds, FA2, having methyl $\left(\mathrm{IC}_{50}=40 \mu \mathrm{g} / \mathrm{mL}\right.$ ), FA8, having p-hydroxyl moiety $\left(\mathrm{IC}_{50}=40\right)$. FA10, having morpholine moiety $\left(\mathrm{IC}_{50}=42 \mu \mathrm{g} / \mathrm{mL}\right)$. The other compounds were also moderately potent but with a higher $\mathrm{IC}_{50}$ values. The potency indicated the importance of halogen in enhancing the cytotoxicity.

\section{Conclusions}

Ferulic acid, a multi-faceted phenolic acid was found to possess wide spectrum of biological activities till date. In light of its therapeutic applications, it’s derivatives (esters and amides), were designed to synthesize and evaluate for their anti cancer activity.

\subsection{Safety Concern}

Ferulic acid is a free carboxylic acid with gastric irritation as inevitable adverse effect when consumed orally and this is our rationale for selecting its simple derivatives (esters and amides), lacking free carboxylic acids and thereby preventing G.I. problems and increasing its lipophilicity and membrane penetration. Till date, no such adverse effects were reported. Additional work is under progress with respect to its drug profile.

\subsection{Significance}

Ferulic acid solely possess very low anti cancer activity and its potency increases manifold only when used in combination with other anti neopastics [15]. Our current work aimed at synthesizing its derivatives (circumventing its commonly found side effect i.e., G. I. problems) and evaluating those derivatives for anticancer activity.

\section{Acknowledgements}

The author is indebted to Sk. Afzal basha, S. Arun Satyadev and K. Kishore Naidu for their support during the course of our work. We express deep sense of gratitude to Principal, A.U college of Pharmaceutical Sciences, 
vizag for providing the needed equipment and support.

\section{References}

[1] Sultana, R. (2012) Ferulic Acid Ethyl Ester as a Potential Therapy in Neurodegenerative Disorders. Biochimica et Biophysica Acta, 1822, 748-752. http://dx.doi.org/10.1016/j.bbadis.2011.10.015

[2] LeBlanc, L.M., Paré, A.F., Jean-François, J., Hébert, M.J.G., Surette, M.E. and Touaibia, M. (2012) Synthesis and Antiradical/Antioxidant Activities of Caffeic Acid Phenethyl Ester and Its Related Propionic, Acetic, and Benzoic Acid Analogues. Molecules, 17, 14637-14650. http://dx.doi.org/10.3390/molecules171214637

[3] Mancuso, C. and Santangelo, R. (2014) Ferulic Acid: Pharmacological and Toxicological Aspects. Food and Chemical Toxicology, 65, 185-195. http://dx.doi.org/10.1016/j.fct.2013.12.024

[4] Kumar, N. and Pruthi, V. (2014) Potential Applications of Ferulic Acid from Natural Sources. Biotechnology Reports, 4, 86-93. http://dx.doi.org/10.1016/j.btre.2014.09.002

[5] Lin, F.-H., Lin, J.-Y., Gupta, R.D., Tournas, J.A., Burch, J.A., Angelica Selim, M., Monteiro-Riviere, N.A., Grichnik, J.M., Zielinski, J. and Pinnell, S.R. Ferulic Acid Stabilizes a Solution of Vitamins C and E and Doubles Its Photoprotection of Skin. The Society for Investigative Dermatology.

[6] Choi, R., et al. (2011) Effect of Ferulic Acid on Diabetic Nephropathyin Rat Model of Type2 Diabetes. EMM Experimental and Molecular Medicine, 43, 676-683. http://dx.doi.org/10.3858/emm.2011.43.12.078

[7] Zhang, P.-X., Lin, H., Qu, C., Tang, Y.-P., Li, N.-G., Kai, J., Shang, G.X., Li, B.Q., Zhang, L., Yan, H., Liu, P. and Duan, J.-A. (2015) Design, Synthesis, and in Vitro Antiplatelet Aggregation Activities of Ferulic Acid Derivatives. Journal of Chemistry, 2015, Article ID: 376527.

[8] Bian, Y.-Y., Guo, J., Majeed, H., Zhu, K.-X., Guo, X.-N., Peng, W. and Zhou, H.-M. (2015) Ferulic Acid Renders Protection to HEK293 Cells against Oxidative Damage and Apoptosis Induced by Hydrogen Peroxide. In Vitro Cellular \& Developmental Biology-Animal, 51, 722-729. http://dx.doi.org/10.1007/s11626-015-9876-0

[9] Srinivasan, M., Sudheer, A.R. and Menon, V.P. (2007) Ferulic Acid: Therapeutic Potential through It’s Anti Oxidant Activity. Journal of Clinical Biochemistry and Nutrition, 40, 92-100.

[10] Kanski, J., Aksenova, M., Stoyanova, A. and Allan Butterfield, D. (2002) Ferulic Acid Antioxidant Protection against Hydroxyl and Peroxyl Radical Oxidation in Synaptosomal and Neuronal Cell Culture Systems in Vitro: Structure-Activity Studies. Journal of Nutritional Biochemistry, 13, 273-281. http://dx.doi.org/10.1016/S0955-2863(01)00215-7

[11] Kobayashi, M., Hirano, T. and Iseki, K. In Vitro and in Vivo Antioxidant Properties of Ferulic Acid: A Comparative Study with Other Natural Oxidation Inhibitors. Food Chemistry.

[12] Khatkar, A., Nanda, A., Kumar, P. and Narasimhan, B. (2015) Synthesis and Antimicrobial Evaluation of Ferulic Acid Derivatives. Research on Chemical Intermediates, 41, 299-309. http://dx.doi.org/10.1007/s11164-013-1192-2

[13] Ferrari, M., Fornasiero, M.C. and Isetta, A.M. (1990) MTT Colorimetric Assay for Testing Macrophage Cytotoxicity Activity in Vitro. Journal of Immunological Method, 131, 165-172.

[14] Ciapetti, G., Cennai, E., Pratelli, L. and Pizzoferrato, A. (1993) In Vitro Evaluatio of Cell/Biomaterial Interaction by MTT Assay. Biomaterials, 14, 359-364.

[15] Choi, Y.E. and Park, E. (2015) Ferulic Acid in Combination with PARP Inhibitor Sensitizes Breastcancer Cells as Chemotherapeutic Strategy. Biochemical and Biophysical Research Communications, 458, e520-e524. 


\section{Abbreviations}

IR: infrared spectroscopy;

str: stretch;

s: singlet,

d: doublet;

m: mutiplet;

MTT: [3-(4,5-di methyl thiazol-2-yl)-2,5-diphenyl tetrazolium bromide;

TLC: thin layer chromatography;

Ar: aromatic;

DMEM: dubelcoccous eagles medium;

MEM: minimum essential media eagle;

UV spectroscopy: ultraviolet spectroscopy;

$\mathrm{IC}_{50}: 50 \%$ inhibitory concentration;

$\mu \mathrm{l}$ : micro liters;

$\mu \mathrm{g} / \mathrm{mL}$ : microgram per ml;

NMR: nuclear magnetic resonance spectroscopy;

THF: tetrahydrofuran;

$\mathrm{CaCl}_{2}$ : calicium chloride. 


\section{Supplementary Data}

\begin{tabular}{|c|c|c|c|c|}
\hline Compound & $\begin{array}{c}\text { Ir spectral data } \\
\text { Position of absorption band } \\
\left(\mathrm{cm}^{-1}\right)\end{array}$ & $\begin{array}{c}{ }^{1} \mathrm{H} \text { NMR } \\
\text { Chemical shift }(\delta) \text { in ppm }\end{array}$ & $\begin{array}{c}{ }^{13} \text { C NMR } \\
\text { Chemical shift }(\delta) \\
\text { in ppm }\end{array}$ & $\begin{array}{c}\text { Mass spectral } \\
\text { data }\end{array}$ \\
\hline FE1 & $\begin{array}{l}3630 \text { (Ar-OH), } 1695 \text { (C=Ostr., } \\
\text { ester), } 3010 \text { (C-H str., aromatic), } \\
1596 \text { (C=C skeletal str., phenyl), } \\
1699 \text { (C=C str., alkene), } 1123 \\
\text { (C-O str. Ester), } 2860 \text { (C-H str., } \\
\text { Ar-OCH }_{3} \text { ) }\end{array}$ & $\begin{array}{l}\text { 5.00 } \mathrm{Ar}-\mathrm{OH}(\mathrm{s} .1 \mathrm{H}), 3.91-\mathrm{OCH}_{3}(\mathrm{~s}, 1 \mathrm{H}) \\
\text { 3.78-ArOCH} \\
\text { 7. } \\
\text { 7.630 }\left(\mathrm{d}, 1 \mathrm{H}, \mathrm{C}_{1} \text { of acrylate, } \mathrm{j}=1.2 \mathrm{~Hz}\right) \text {, } \\
6.90\left(\mathrm{~d}, 1 \mathrm{H}, \mathrm{C}_{2} \text { of acrylate, j = } 8 \mathrm{~Hz}\right) \\
6.37 \mathrm{Ar}-\mathrm{H}(\mathrm{d}, 1 \mathrm{H}, \mathrm{j}=1.6 \mathrm{~Hz}) \\
6.925 \mathrm{Ar}-\mathrm{H}(\mathrm{d}, 1 \mathrm{H}, \mathrm{j}=1.6 \mathrm{~Hz})\end{array}$ & $\begin{array}{l}\text { 144.9(C1), } \\
\text { 151.3(C2), } \\
\text { 112.0(C3), } \\
\text { 143.7(C1') } \\
\text { 118.1(C2') } \\
\text { 166.5(C3’) } \\
\text { 56.2(C4') }\end{array}$ & $\begin{array}{c}\text { Molecular ion } \\
\text { peak at } 209\end{array}$ \\
\hline FE2 & $\begin{array}{l}3600 \text { (Ar-OH), } 1685 \text { (C=Ostr., } \\
\text { ester), } 3004 \text { (C-H str., aromatic), } \\
1592 \text { (C=C skeletal str., phenyl), } \\
1689 \text { (C=C str., alkene), } 1080 \\
\text { (C-O str. Ester), } 2842 \\
\left.\text { (C-H str., Ar-OCH }{ }_{3}\right)\end{array}$ & $\begin{array}{l}\text { 5.27 } \mathrm{Ar}-\mathrm{OH}(\mathrm{s} .1 \mathrm{H}), 3.88 \mathrm{OCH}_{3}(\mathrm{~s}, 1 \mathrm{H}) \text {, } \\
\text { 3.88- } \mathrm{ArOCH}_{3}(\mathrm{~s}, 3 \mathrm{H}) \text {, } \\
\text { 7.010 }\left(\mathrm{d}, 1 \mathrm{H}, \mathrm{C}_{1} \text { of acrylate, } \mathrm{j}=4 \mathrm{~Hz}\right) \text {, } \\
6.890\left(\mathrm{~s}, 1 \mathrm{H}, \mathrm{C}_{2} \text { of acrylate }\right) \\
\text { 6.256 } \mathrm{Ar}-\mathrm{H}(\mathrm{d}, 1 \mathrm{H} \mathrm{j}=\mathrm{Hz}) \\
6.890 \mathrm{Ar}-\mathrm{H}(\mathrm{d}, 1 \mathrm{H} \mathrm{j}=0.8 \mathrm{~Hz})\end{array}$ & $\begin{array}{l}\text { 144.9(C1), } \\
\text { 151.3(C2), } \\
\text { 112.0(C3), } \\
\text { 145.7(C1') } \\
\text { 116.1(C2') } \\
\text { 166.5(C3') } \\
61.4(\mathrm{C} 4 ') \\
14.2(\mathrm{C} 5 ') \\
\text { 56.2(C4') }\end{array}$ & $\begin{array}{c}\text { Molecular ion } \\
\text { peak at } 223\end{array}$ \\
\hline FE3 & $\begin{array}{l}3620 \text { (Ar-OH), } 1675 \text { (C=Ostr., } \\
\text { ester), } 3006 \text { (C-H str., aromatic), } \\
1589 \text { (C=C skeletal str., phenyl), } \\
1685 \text { (C=C str., alkene), } 1095 \\
\text { (C-O str. Ester), } 2946 \\
\text { (C-H str., Ar-OCH }{ }_{3} \text { ) } \\
710.94 \text { ( long chain band) }\end{array}$ & $\begin{array}{l}5.890(1 \mathrm{H} \text { s } \mathrm{Ar}-\mathrm{OH}), 3.924\left(1 \mathrm{H}, \mathrm{s}, \mathrm{OCH}_{3}\right) \text {, } \\
\text { 3.88- } \mathrm{ArOCH} \mathrm{CH}_{3}(\mathrm{~s}, 3 \mathrm{H}) \text {, } \\
\left.\text { 7.059 (d, } 1 \mathrm{H}, \mathrm{C}_{1} \text { of acrylate, } \mathrm{j}=3.6 \mathrm{~Hz}\right) \text {, } \\
6.275\left(\mathrm{~s}, 1 \mathrm{H}, \mathrm{C}_{2} \text { of acrylate }\right) \\
6.904 \mathrm{Ar}-\mathrm{H}(\mathrm{d}, 1 \mathrm{H} \mathrm{j}=1.2 \mathrm{~Hz}) \\
7.036 \mathrm{Ar}-\mathrm{H}(\mathrm{d}, 1 \mathrm{H} \mathrm{j}=4.4 \mathrm{~Hz}) \\
1.012 \mathrm{CH}_{3} \text { of propyl chain, }(\mathrm{m} 3 \mathrm{H}) \\
\text { 1.682 } \mathrm{CH}_{2} \text { of propyl chain, }(\mathrm{m}, 2 \mathrm{H}) \\
\text { 4.174 } \mathrm{CH}_{2} \text { of propyl chain, }(\mathrm{m}, 2 \mathrm{H})\end{array}$ & $\begin{array}{l}\text { 144.9(C1), } \\
\text { 152.3(C2), } \\
\text { 116.3(C3), } \\
\text { 56.2(C4') } \\
\text { 148.7(C1') } \\
118.1\left(\mathrm{C} 2^{\prime}\right) \\
169.5(\mathrm{C} 3 ') \\
67.6(\mathrm{C} 4 ') \\
\text { 22.2(C5') } \\
\text { 10.2(C6') }\end{array}$ & $\begin{array}{c}\text { Molecular ion } \\
\text { peak at } 237\end{array}$ \\
\hline FE4 & $\begin{array}{l}3625 \text { (Ar-OH), } 1679 \text { (C=O str., } \\
\text { ester), } 3010 \text { (C-H str., aromatic), } \\
1565 \text { (C=C skeletal str., phenyl), } \\
1695 \text { (C=C str., alkene), } 1099 \\
\text { (C-O str. Ester), } 2846 \\
\text { (C-H str., Ar-OCH }{ }_{3} \text { ) } \\
750.94 \text { (long chain band) }\end{array}$ & $\begin{array}{l}5.813(1 \mathrm{H} \mathrm{s} \mathrm{Ar}-\mathrm{OH}), \\
3.907\left(1 \mathrm{H}, \mathrm{s}, \mathrm{OCH}_{3}\right), \\
\text { 3.907- } \mathrm{ArOCH}_{3}(\mathrm{~s}, 3 \mathrm{H}), \\
7.044\left(\mathrm{~d}, 1 \mathrm{H}, \mathrm{C}_{1} \text { ofacrylate, } \mathrm{j}=16 \mathrm{~Hz}\right), \\
7.570\left(\mathrm{~s}, 1 \mathrm{H}, \mathrm{C}_{2} \text { of acrylate) }\right. \\
6.246 \mathrm{Ar}-\mathrm{H}(\mathrm{d}, 1 \mathrm{H} \mathrm{j}=2.4 \mathrm{~Hz}) \\
6.896 \mathrm{Ar}-\mathrm{H}(\mathrm{d}, 1 \mathrm{H} \mathrm{j}=8 \mathrm{~Hz}) \\
1.312 \mathrm{CH}_{3} \text { of propyl chain, }(\mathrm{m}, 6 \mathrm{H}) \\
5.084-5.162 \mathrm{CH}_{2} \text { of propyl chain, }(\mathrm{m})\end{array}$ & $\begin{array}{l}\text { 147.9(C1), } \\
\text { 155.3(C2), } \\
\text { 119.3(C3), } \\
\text { 56.2(C4') } \\
\text { 152.7(C1') } \\
\text { 122.1(C2') } \\
\text { 168.5(C3') } \\
\text { 69.6(C5') } \\
\text { 24.2(C6'.C7') }\end{array}$ & $\begin{array}{c}\text { Molecular ion } \\
\text { peak at } 237\end{array}$ \\
\hline FE5 & $\begin{array}{l}3629 \text { (Ar-OH), } 1685 \text { (C=Ostr., } \\
\text { ester), } 3003 \text { (C-H str., aromatic), } \\
1575 \text { (C=C skeletal str., phenyl), } \\
1687 \text { (C=C str., alkene), } 1095 \\
\text { (C-O str. Ester), } 2946 \\
\text { (C-H str., Ar-OCH }{ }_{3} \text { ) } \\
718.94 \text { (long chain band) }\end{array}$ & $\begin{array}{l}5.890(1 \mathrm{H} \mathrm{s} \mathrm{Ar}-\mathrm{OH}), \\
\text { 3.923-ArOCH }(\mathrm{s}, 3 \mathrm{H}), \\
7.056\left(\mathrm{~d}, 1 \mathrm{H}, \mathrm{C}_{1} \text { of acrylate, } \mathrm{j}=2 \mathrm{~Hz}\right), \\
7.584\left(\mathrm{~d}, 1 \mathrm{H}, \mathrm{C}_{2} \text { of acrylate, } \mathrm{j}=16 \mathrm{~Hz}\right) \\
6.307 \mathrm{Ar}-\mathrm{H}(\mathrm{d}, 1 \mathrm{H} \mathrm{j}=16 \mathrm{~Hz}) \\
6.922 \mathrm{Ar}-\mathrm{H}(\mathrm{d}, 1 \mathrm{H} \mathrm{j}=6 \mathrm{~Hz}) \\
0.98 \mathrm{CH}_{3} \text { of butyl chain, }(\mathrm{m} 3 \mathrm{H}) \\
1.465-1.409(\mathrm{~m}) \mathrm{CH}_{2} \text { of butyl chain, } \\
1.720-1.625(\mathrm{~m}) \mathrm{CH}_{2} \text { of butyl chain, }\end{array}$ & $\begin{array}{l}\text { 147.9(C1), } \\
\text { 155.3(C2), } \\
\text { 119.3(C3), } \\
\text { 152.7(C1') } \\
\text { 122.1(C2') } \\
\text { 168.5(C3’) } \\
\text { 56.2(C4') } \\
\text { 65.1(C5') } \\
\text { 31.3(C6’). } \\
\text { 19.0(C7’) } \\
\text { 13.8(C8') }\end{array}$ & $\begin{array}{c}\text { Molecular ion } \\
\text { peak at } 251\end{array}$ \\
\hline FE6 & $\begin{array}{l}3625 \text { (Ar-OH), } 1689 \text { (C=Ostr., } \\
\text { ester), } 3009 \text { (C-H str., aromatic), } \\
1565 \text { (C=C skeletal str., phenyl), } \\
1697 \text { (C=C str., alkene), } 1085 \\
\text { (C-O str. Ester), } 2956 \\
\text { (C-H str., Ar-OCH }{ }_{3} \text { ) } \\
613.94 \text { (long chain band) }\end{array}$ & 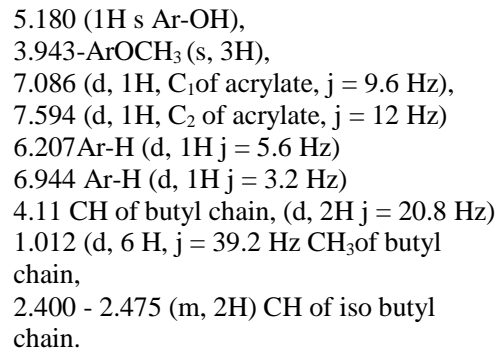 & $\begin{array}{l}\text { 149.9(C1), } \\
\text { 150.3(C2), } \\
\text { 117.3(C3), } \\
\text { 155.7(C1') } \\
\text { 120.1(C2') } \\
\text { 167.5(C3') } \\
\text { 74.9(C4') } \\
\text { 27.8(C5'). } \\
\text { 19.4(C6') } \\
\text { 19.4(C7') }\end{array}$ & $\begin{array}{c}\text { Molecular ion } \\
\text { peak at } 251\end{array}$ \\
\hline
\end{tabular}




\section{Continued}

FE7

FE9

FE10

FE11
3630 (Ar-OH), 1669 (C=Ostr., ester), 3019 (C-H str., aromatic), 1569 (C=C skeletal str., phenyl), 1699 (C=C str., alkene), 1198

(C-O str. Ester), 2856

(C-H str., $\mathrm{Ar}-\mathrm{OCH}_{3}$ )

608.94 (long chain band)

3625 (Ar-OH), 1689 (C=Ostr., ester), 3009 (C-H str., aromatic), 1565 (C=C skeletal str., phenyl), 1697 (C=C str., alkene), 1085

(C-O str. Ester), 2956

(C-H str., $\mathrm{Ar}-\mathrm{OCH}_{3}$ )

613.94 ( long chain band)

3625 (Ar-OH), 1689 (C=Ostr., ester), 3009 (C-H str., aromatic), 1565 ( $\mathrm{C}=\mathrm{C}$ skeletal str., phenyl), 1697 (C=C str., alkene), 1085

(C-O str. Ester), 2956

(C-H str., $\left.\mathrm{Ar}-\mathrm{OCH}_{3}\right)$ 613.94 (long chain band)

3630 (Ar-OH), 1669 (C=Ostr., ester), 3019 (C-H str., aromatic), 1569 (C=C skeletal str., phenyl), 1687 (C=C str., alkene), 1152 (C-O str. Ester), 2966 (C-H str., $\mathrm{Ar}-\mathrm{OCH}_{3}$ ) 570.94 (chlorine)

3615 (Ar-OH), 1699 (C=Ostr., ester), 3019 (C-H str., aromatic), 1569 (C=C skeletal str., phenyl), 1677 (C=C str., alkene), 1255

(C-O str. Ester), 2956

(C-H str., $\mathrm{Ar}-\mathrm{OCH}_{3}$ )

613.94 (bromine)
$5.28(1 \mathrm{H} \mathrm{s} \mathrm{Ar}-\mathrm{OH})$,

3.73- $\mathrm{ArOCH}_{3}(\mathrm{~s}, 3 \mathrm{H})$,

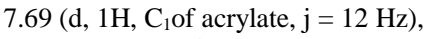

$6.49\left(\mathrm{~d}, 1 \mathrm{H}, \mathrm{C}_{2}\right.$ of acrylate, , j = $12 \mathrm{~Hz}$ ),

$6.59 \mathrm{Ar}-\mathrm{H}(\mathrm{d}, 1 \mathrm{H} \mathrm{j}=8 \mathrm{~Hz})$

$6.84 \mathrm{Ar}-\mathrm{H}(\mathrm{d}, 1 \mathrm{H} \mathrm{j}=20 \mathrm{~Hz})$

$1.40 \mathrm{CH}_{3}$ protons of t-butyl group $(9 \mathrm{H}, \mathrm{s})$

$5.280(1 \mathrm{H} \mathrm{s} \mathrm{Ar}-\mathrm{OH})$,

3.943- $\mathrm{ArOCH}_{3}(\mathrm{~s}, 3 \mathrm{H})$,

7.086 (d, $1 \mathrm{H}, \mathrm{C}_{1}$ of acrylate, $\mathrm{j}=3.6 \mathrm{~Hz}$ ),

$7.594\left(\mathrm{~d}, 1 \mathrm{H}, \mathrm{C}_{2}\right.$ of acrylate, $\left.\mathrm{j}=1.6 \mathrm{~Hz}\right)$

$6.207 \mathrm{Ar}-\mathrm{H}(\mathrm{d}, 1 \mathrm{H} \mathrm{j}=2 \mathrm{~Hz})$

$6.944 \mathrm{Ar}-\mathrm{H}(\mathrm{d}, 1 \mathrm{H} \mathrm{j}=2.4 \mathrm{~Hz})$

$1.33 \mathrm{CH}_{2}$ protons of pentyl chain $(2 \mathrm{H}, \mathrm{m})$

$1.29 \mathrm{CH}_{2}$ protons of pentyl chain $(2 \mathrm{H}, \mathrm{m})$

$1.59 \mathrm{CH}_{2}$ protons of pentyl chain $(2 \mathrm{H}, \mathrm{m})$

$4.29 \mathrm{CH}_{2}$ protons of pentyl chain $(2 \mathrm{H}, \mathrm{m})$

$0.98 \mathrm{CH}_{3}$ protons of pentyl chain $(3 \mathrm{H}, \mathrm{m})$.

$5.880(1 \mathrm{H} \mathrm{s} \mathrm{Ar}-\mathrm{OH})$,

3.943- $\mathrm{ArOCH}_{3}(\mathrm{~s}, 3 \mathrm{H})$,

$6.086\left(\mathrm{~d}, 1 \mathrm{H}, \mathrm{C}_{1}\right.$ of acrylate, $\left.\mathrm{j}=25.6 \mathrm{~Hz}\right)$,

7.694 (s, $1 \mathrm{H}, \mathrm{C}_{2}$ of acrylate)

$6.207 \mathrm{Ar}-\mathrm{H}(\mathrm{d}, 1 \mathrm{H} \mathrm{j}=2 \mathrm{~Hz})$

$6.944 \mathrm{Ar}-\mathrm{H}(\mathrm{d}, 1 \mathrm{H} \mathrm{j}=18 \mathrm{~Hz})$

$1.40 \mathrm{CH}_{2}$ of pentyl chain, $(\mathrm{m} 3 \mathrm{H})$

$4.13(\mathrm{~m}, 1 \mathrm{H}) \mathrm{CH}$ of pentyl chain,

$1.53(\mathrm{~m}, 2 \mathrm{H}) \mathrm{CH}_{2}$ of pentyl chain.

$1.33(\mathrm{~m}, 2 \mathrm{H}) \mathrm{CH}_{2}$ of pentyl chain.

$0.96(t, 3 \mathrm{H}) \mathrm{CH}_{3}$ of pentyl chain.

$5.880(1 \mathrm{H} \mathrm{s} \mathrm{Ar}-\mathrm{OH})$,

3.943- $-\mathrm{ArOCH}_{3}(\mathrm{~s}, 3 \mathrm{H})$,

7.486 (d, $1 \mathrm{H}, \mathrm{C}_{1}$ of acrylate, $\mathrm{j}=13.6 \mathrm{~Hz}$ ),

$7.524\left(\mathrm{~d}, 1 \mathrm{H}, \mathrm{C}_{2}\right.$ of acrylate, $\mathrm{j}=2 \mathrm{~Hz}$ )

$6.507 \mathrm{Ar}-\mathrm{H}(\mathrm{d}, 1 \mathrm{H} \mathrm{j}=4.4 \mathrm{~Hz})$

$6.844 \mathrm{Ar}-\mathrm{H}(\mathrm{d}, 1 \mathrm{H} \mathrm{j}=2.4 \mathrm{~Hz})$

4.41- $-\mathrm{CH}_{2}(\mathrm{~d}, 2 \mathrm{H}, \mathrm{j}=3.6 \mathrm{~Hz})$

$3.66-\mathrm{CH}_{2}(\mathrm{~d}, 2 \mathrm{H}, \mathrm{j}=24 \mathrm{~Hz})$

5.680 (s, $1 \mathrm{H}, \mathrm{Ar}-\mathrm{OH})$,

3.743- $\mathrm{ArOCH}_{3}(\mathrm{~s}, 3 \mathrm{H})$,

6.41 (d, $1 \mathrm{H}, \mathrm{C}_{1}$ of acrylate, $\mathrm{j}=16 \mathrm{~Hz}$ ),

$7.641\left(\mathrm{~d}, 1 \mathrm{H}, \mathrm{C}_{2}\right.$ of acrylate, $\left.\mathrm{j}=20 \mathrm{~Hz}\right)$

$6.69 \mathrm{Ar}-\mathrm{H}(\mathrm{d}, 1 \mathrm{H}, \mathrm{j}=3.2 \mathrm{~Hz})$

$6.84 \mathrm{Ar}-\mathrm{H}(\mathrm{d}, 1 \mathrm{H}, \mathrm{j}=20 \mathrm{~Hz})$

$4.65\left(\mathrm{~d}, 2 \mathrm{H}, \mathrm{CH}_{2}, \mathrm{j}=28 \mathrm{~Hz}\right)$

$3.58\left(\mathrm{~d}, 2 \mathrm{H}, \mathrm{CH}_{2}, \mathrm{j}=32 \mathrm{~Hz}\right)$
149.9(C1),

150.3(C2),

117.3(C3),

155.7(C1')

120.1(C2')

167.5(C3')

82.2(C4')

28.9(C5', C6', C7')

149.9(C1),

150.3(C2),

117.3(C3),

155.7(C1')

120.1(C2')

167.5(C3')

65.4(C4')

28.8(C5').

28.1(C6')

22.5(C7')

14.1(C8')

149.9(C1),

150.3(C2),

117.3(C3),

155.7(C1')

120.1(C2')

167.5(C3')

71.9(C4')

21.8(C5').

39.4(C6')

16.4(C7')

14.1(C8')

149.9(C1)

155.3(C2)

127.3(C3)

151.9(C1')

118.5(C2')

173.5(C3')

69.6(C4')

42.4(C5')

150.9(C1)

155.3(C2)

119.3(C3)

159.7(C1')

119.1(C2')

169.5(C3')

70.6(C4')

20.4(C5')
Molecular ion peak at 251

Molecular ion peak at 265

Molecular ion peak at 265

Molecular ion peak at 257

Molecular ion peak at 302

\section{Elemental Analysis Data of Ferulic Esters}

\begin{tabular}{|c|c|c|c|c|c|c|}
\hline \multirow{2}{*}{ Compound } & \multicolumn{3}{|c|}{ \%Calculated } & \multicolumn{3}{|c|}{$\%$ Found } \\
\hline & C & $\mathbf{H}$ & $\mathbf{O}$ & C & $\mathbf{H}$ & $\mathbf{O}$ \\
\hline FE1 & 63.45 & 5.81 & 30.74 & 63.43 & 5.79 & 30.71 \\
\hline FE2 & 64.85 & 6.35 & 28.80 & 64.81 & 6.33 & 28.79 \\
\hline FE3 & 66.09 & 6.83 & 27.09 & 66.06 & 6.81 & 27.06 \\
\hline FE4 & 66.09 & 6.83 & 27.09 & 66.05 & 6.80 & 27.04 \\
\hline FE5 & 67.18 & 7.25 & 25.57 & 67.15 & 7.23 & 25.54 \\
\hline FE6 & 67.18 & 7.25 & 25.57 & 67.12 & 7.20 & 25.50 \\
\hline FE7 & 67.18 & 7.25 & 25.57 & 67.11 & 7.22 & 25.51 \\
\hline
\end{tabular}




\section{Continued}

\begin{tabular}{|c|c|c|c|c|c|c|}
\hline FE8 & 68.16 & 7.63 & 24.21 & 68.14 & 7.62 & 24.22 \\
\hline FE9 & 68.16 & 7.63 & 24.21 & 68.19 & 7.59 & 24.10 \\
\hline FE10 & 56.15 & 5.10 & 24.93 & 56.10 & 5.15 & 24.99 \\
\hline FE11 & 47.86 & 4.35 & 21.25 & 47.90 & 4.30 & 47.85 \\
\hline
\end{tabular}

Elemental Analysis Data of Ferulic Amides

\begin{tabular}{|c|c|c|c|c|c|c|c|c|c|}
\hline \multirow{2}{*}{\multicolumn{2}{|c|}{ Compound }} & \multicolumn{4}{|c|}{ \%Calculated } & \multicolumn{4}{|c|}{$\%$ Found } \\
\hline & & C & $\mathbf{H}$ & $\mathbf{O}$ & $\mathbf{N}$ & C & $\mathbf{H}$ & $\mathbf{O}$ & $\mathbf{N}$ \\
\hline \multicolumn{2}{|l|}{ FA1 } & 62.17 & 5.74 & 24.84 & 7.25 & 62.19 & 5.77 & 24.87 & 7.29 \\
\hline \multicolumn{2}{|l|}{ FA2 } & 63.36 & 6.32 & 23.16 & 6.76 & 63.39 & 6.39 & 23.18 & 6.78 \\
\hline \multicolumn{2}{|l|}{ FA3 } & 65.14 & 6.83 & 21.69 & 6.33 & 65.10 & 6.85 & 21.72 & 6.30 \\
\hline \multicolumn{2}{|l|}{ FA4 } & 72.07 & 6.05 & 16.94 & 4.94 & 72.10 & 6.08 & 16.99 & 4.89 \\
\hline \multicolumn{2}{|l|}{ FA5 } & 71.36 & 5.61 & 17.82 & 5.20 & 71.30 & 5.69 & 17.89 & 5.29 \\
\hline \multicolumn{2}{|l|}{ FA6 } & 60.54 & 4.18 & 14.23 & 4.25 & 60.50 & 4.11 & 14.22 & 4.20 \\
\hline \multicolumn{2}{|l|}{ FA7 } & 69.38 & 4.79 & 16.31 & 9.52 & 69.30 & 4.70 & 16.30 & 9.58 \\
\hline \multicolumn{2}{|l|}{ FA8 } & 67.36 & 5.30 & 22.43 & 4.91 & 67.39 & 5.35 & 22.49 & 4.85 \\
\hline \multicolumn{2}{|l|}{ FA9 } & 67.76 & 5.35 & 15.93 & 4.65 & 67.69 & 5.30 & 15.90 & 4.69 \\
\hline \multicolumn{2}{|l|}{ FA10 } & 63.87 & 6.51 & 24.31 & 5.32 & 63.79 & 6.50 & 24.39 & 5.38 \\
\hline Compound & \multicolumn{3}{|c|}{$\begin{array}{c}\text { Ir spectral data } \\
\text { Position of absorption band }\left(\mathrm{cm}^{-1}\right)\end{array}$} & \multicolumn{3}{|c|}{$\begin{array}{c}{ }^{1} \mathrm{H} \text { NMR } \\
\text { Chemical shift }(\delta) \text { in ppm }\end{array}$} & \multicolumn{2}{|c|}{$\begin{array}{c}{ }^{13} \mathrm{C} \text { NMR } \\
\text { Chemical shift }(\delta) \\
\text { in ppm }\end{array}$} & $\begin{array}{l}\text { Mass spectral } \\
\text { data }\end{array}$ \\
\hline FA1 & $\begin{array}{l}362 \\
310 \\
163 \\
\text { str. } \\
158 \\
1, € \\
\text { str. }\end{array}$ & $\begin{array}{l}\text { H), } \\
\text { tr., amide } \\
\text { c), } \\
\text { keletal s } \\
\text { str., alke } \\
\mathrm{I}_{3} \text { ) }\end{array}$ & (C-H & $\begin{array}{l}\text { 5.20 Ar-OI } \\
3.88-\mathrm{ArOC} \\
7.09(\mathrm{~d}, 1 \mathrm{H} \\
6.290(\mathrm{~d}, 1 \\
6.67 \mathrm{Ar}-\mathrm{H} \\
6.825 \mathrm{Ar}-\mathrm{H} \\
6.005(\mathrm{~s}, 2\end{array}$ & $\begin{array}{l}\mathrm{H}), 3.9 \\
3 \mathrm{H}) \\
\mathrm{f} \text { acryla } \\
\text { of acry } \\
\mathrm{H}, \mathrm{j}=28 \\
\mathrm{H} \mathrm{j}=2 \\
\left.\mathrm{H}_{2}\right)\end{array}$ & $\begin{array}{l}\mathrm{H}_{3}(\mathrm{~s}, 1 \mathrm{H}) \\
\mathrm{j}=2 \mathrm{~Hz}) \\
\mathrm{j}=2 \mathrm{~Hz})\end{array}$ & \multicolumn{2}{|c|}{$\begin{array}{c}\text { 144.9(C1) } \\
151.3(\mathrm{C} 2) \\
112.0(\mathrm{C} 3) \\
128.1(\mathrm{C} 4) \\
120.1(\mathrm{C} 5) \\
116.2(\mathrm{C} 6) \\
144.9(\mathrm{C} 1 ') \\
116.1(\mathrm{C} 2 ') \\
169.5(\mathrm{C} 3 ') \\
56.8(\mathrm{C} 4 ')\end{array}$} & $\begin{array}{l}\text { Molecular ion } \\
\text { peak-194 }\end{array}$ \\
\hline FA2 & \multicolumn{3}{|c|}{$\begin{array}{l}3630(\mathrm{Ar}-\mathrm{OH}), \\
3119\left(\mathrm{NH}_{2}\right), \\
1653(\mathrm{C}=\mathrm{Ostr} ., \text { amide) } 3018 \text { (C-H str., } \\
\text { aromatic), } \\
1565(\mathrm{C}=\mathrm{C} \text { skeletal str., phenyl), } \\
1689(\mathrm{C}=\mathrm{C} \text { str., alkene), } 2865 \text { (C-H } \\
\left.\text { str., } \mathrm{Ar}-\mathrm{OCH}{ }_{3}\right) \\
2855\left(\mathrm{CH}_{3} \text { str., ) }\right.\end{array}$} & $\begin{array}{l}5.88 \mathrm{Ar}-\mathrm{OH} \\
3.45-\mathrm{ArOC} \\
7.29(\mathrm{~d}, 1 \mathrm{H} \\
6.390(\mathrm{~d}, 1 \\
6.77 \mathrm{Ar}-\mathrm{H} \\
6.925 \mathrm{Ar}-\mathrm{H} \\
8.005(\mathrm{~s}, 2 . \\
2.75(\mathrm{~s}, 3 \mathrm{H}\end{array}$ & $\begin{array}{l}\mathrm{H}), 3.7 \\
3 \mathrm{H}), \\
\mathrm{f} \text { acryla } \\
\text { of acry } \\
\mathrm{H} \mathrm{j}=8 \mathrm{H} \\
\mathrm{H} \mathrm{j}=2 \\
\left.\mathrm{H}_{2}\right) \\
\text { ) }\end{array}$ & $\begin{array}{l}\mathrm{H}_{3}(\mathrm{~s}, 1 \mathrm{H}) \\
12 \mathrm{~Hz}) \\
=2 \mathrm{~Hz})\end{array}$ & $\begin{array}{l}14 \\
15 \\
111 \\
12 \\
12 \\
118 \\
145 \\
118 \\
167 \\
57\end{array}$ & & $\begin{array}{l}\text { Molecular ion } \\
\text { peak-208 }\end{array}$ \\
\hline FA3 & $\begin{array}{l}36 \\
310 \\
168 \\
\text { aro } \\
156 \\
165 \\
\text { str. } \\
285 \\
27\end{array}$ & $\begin{array}{l}\text { H), } \\
\text { tr., amide } \\
\text { keletal s } \\
\text { tr., alken } \\
\text { t }_{3} \text { ) } \\
\text { tr.,) } \\
\text { tr.,) }\end{array}$ & $\begin{array}{l}\text { C-H str., } \\
\text { (C-H }\end{array}$ & $\begin{array}{l}5.25 \mathrm{Ar}-\mathrm{OH} \\
3.04-\mathrm{ArOC} \\
7.55(\mathrm{~d}, 1 \mathrm{H} \\
6.84(\mathrm{~d}, 1 \mathrm{H} \\
6.75 \mathrm{Ar}-\mathrm{H} \\
6.89 \mathrm{Ar}-\mathrm{H} \\
8.102(\mathrm{~s}, 2 \\
3.50(\mathrm{~d}, 2 \mathrm{H} \\
1.35(\mathrm{~d}, 3 \mathrm{H}\end{array}$ & $\begin{array}{l}\mathrm{H}), 3.59 \\
3 \mathrm{H}), \\
\mathrm{f} \text { acryla } \\
\text { of acryl } \\
\mathrm{H} \mathrm{j}=16 \\
\mathrm{H}, \mathrm{j}=2 \\
\left.\mathrm{H}_{2}\right) \\
\text { 2) } \\
\left.{ }_{3}\right)\end{array}$ & $\begin{array}{l}\mathrm{H}_{3}(\mathrm{~s}, 1 \mathrm{H}), \\
12 \mathrm{~Hz}) \\
=20 \mathrm{~Hz})\end{array}$ & $\begin{array}{l}144 \\
153 \\
112 \\
12 \\
12 \\
11 \\
149 \\
116 \\
169 \\
57 \\
34 \\
15\end{array}$ & & $\begin{array}{l}\text { Molecular ion } \\
\text { peak-222 }\end{array}$ \\
\hline
\end{tabular}




\section{Continued}

3625 (Ar-OH),

$3389\left(\mathrm{NH}_{2}\right)$,

1679 (C=Ostr., amide) 3104 (C-H str.,

FA5 aromatic),

1375 (C=C skeletal str., phenyl), 1665(C=C str., alkene), 2885 (C-H str., $\left.\mathrm{Ar}-\mathrm{OCH}_{3}\right)$ 1604, 1475 (str., C=C aromatic)
5.35Ar-OH(s.1H), 3.79- $\mathrm{OCH}_{3}(\mathrm{~s}, 1 \mathrm{H})$, 3.25- $\mathrm{ArOCH}_{3}(\mathrm{~s}, 3 \mathrm{H})$

7.58(d, $1 \mathrm{H}, \mathrm{C}_{1}$ of acrylate, $\mathrm{j}=16 \mathrm{~Hz}$ ), $6.95\left(\mathrm{~s}, 1 \mathrm{H}, \mathrm{C}_{2}\right.$ of acrylate) $6.65 \mathrm{Ar}-\mathrm{H}(\mathrm{d}, 1 \mathrm{H} \mathrm{j}=12 \mathrm{~Hz})$ $6.94 \mathrm{Ar}-\mathrm{H}(\mathrm{d}, 1 \mathrm{H} \mathrm{j}=20 \mathrm{~Hz})$ 8.102(s, $\left.2 \mathrm{H}, \mathrm{NH}_{2}\right)$ $4.25\left(\mathrm{~d}, 2 \mathrm{H}, \mathrm{CH}_{2}\right)$

7.063(d, 2H, Ar-CH, j = $23.6 \mathrm{~Hz}$ )

7.142(t, 2H, Ar-CH)
144.9(C1),

153.8(C2),

112.8(C3),

129.9(C4)

124.4(C5)

116.5(C6)

149.4(C1')

116.9(C2')

169.3(C3')

44.1(C4')

141.7(C1")

127.58(C2, 6”)

126.25(C4”)

128.32(C3, 5”)

142.7(C1),

155.2(C2),

116.1(C3),

128.0(C4)

123.4(C5)

118.5(C6)

145.4(C1')

118.9(C2')

166.3(C3')

56.9(C4')

135.9(C1”)

121.6(C2, 6")

124.4(C4”)

129.3(C3, 5”)

142.7(C1)

155.2(C2),

116.1(C3),

128.0(C4)

123.4(C5)

118.5(C6)

145.4(C1')

118.9(C2')

166.3(C3')

139.8(C1")

121.8.6(C2, 6")

126.6(C4")

125.4(C3, 5”)

124.2( $\mathrm{C}$ in $\left.\mathrm{CF}_{3}\right)$

144.7(C1)

157.2(C2),

118.1(C3),

122.0(C4)

125.4(C5)

116.5(C6)

145.4(C1')

118.9(C2')

166.3(C3')

56.2(C4')

140.8(C1”)

122.3(C2, 6”)

108.2(C4")

132.4(C3, 5”)

115.8 ( $\mathrm{C}$ in $\mathrm{CN}$ )
Molecular ion peak-284

Molecular ion peak-

270

Molecular ion peak338

Molecular ion peak-295 


\section{Continued}

3572 (Ar-OH),

3572 (Ar-OH),

$3146\left(\mathrm{NH}_{2}\right)$,

1643 (C=Ostr., amide) 3105(C-H str.,

FA8 aromatic),

1325 ( $\mathrm{C}=\mathrm{C}$ skeletal str., phenyl), 1636, (C=C str., alkene), 2345 (C-H str., $\left.\mathrm{Ar}-\mathrm{OCH}_{3}\right)$

1510, 1435 (str., C=C aromatic )

$3146\left(\mathrm{NH}_{2}\right)$,

1643 (C=Ostr., amide) 3105 (C-H str., aromatic),

FA9 1325 (C=C skeletal str., phenyl),

1636, (C=C str., alkene), , 2345 (C-H

str., $\left.\mathrm{Ar}-\mathrm{OCH}_{3}\right)$

1510, 1435 (str., C=C aromatic )

1377 ( str., C-F)

3650 (Ar-OH),

$350(\mathrm{NH})$,

1635 (C=Ostr., amide) 3089 (C-H str.,

FA10 aromatic),

1377 ( $\mathrm{C}=\mathrm{C}$ skeletal str., phenyl),

1655, (C=C str., alkene), , 2345 (C-H

str., sAr- $\left.\mathrm{OCH}_{3}\right)$

1324 (str., C-N)
142.7(C1),

155.2(C2),

116.1(C3),

128.0(C4)

123.4(C5)

118.5(C6)

145.4(C1')

118.9(C2')

166.3(C3')

128.5(C1")

123.5(C2, 6")

154.1(C4")

116.2(C3, 5”)

142.7(C1),

155.2(C2),

116.1(C3),

128.0(C4)

123.4(C5)

118.5(C6)

145.4(C1')

118.9(C2')

166.3(C3')

44.1 $\left(-\mathrm{CH}_{2}\right)$

137.3.5(C1")

128.6(C2, 6")

160.9(C4")

115.3(C3, 5”)

140.7(C1),

159.2(C2),

118.1(C3),

127.0(C4)

125.4(C5)

119.5(C6)

142.4(C1')

116.9(C2')

167.3(C3')

45.6(C1"C4”)

66.8(C2”C3”)
Molecular ion peak-286

Molecular ion peak-320

molecular ion peak-264 